\title{
Natural Basis for the Proliferation of Malaria Vectors in Northern Benin (West Africa)
}

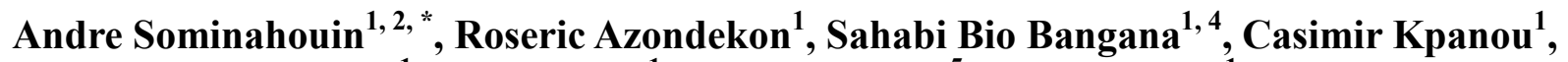 \\ Germain Gil Padonou ${ }^{1}$, Razaki Osse ${ }^{1}$, Benoît Assogba ${ }^{5}$, Fiacre Agossa ${ }^{1}$, Filemon Tokponon ${ }^{6}$, \\ Martin Cossi Akogbéto ${ }^{1,3}$ \\ ${ }^{1}$ Entomological Research Center of Cotonou, Cotonou, Bénin \\ ${ }^{2}$ Department of Geography and Spatial Planning, University of Abomey-Calavi, Abomey-Calavi, Benin \\ ${ }^{3}$ Faculty of Science and Technology, University of Abomey Calavi, Abomey-Calavi, Benin \\ ${ }^{4}$ Valley School of Aquaculture, the National University of Agriculture, Ketou, Benin \\ ${ }^{5}$ Public Health Research Institute, University of Abomey Calavi, Ouidah, Benin \\ ${ }^{6}$ Ministry of Health, National Malaria Control Program (NMCP), Cotonou, Benin
}

Email address:

andrsominahouin@yahoo.fr (A. Sominahouin)

${ }^{*}$ Corresponding author

\section{To cite this article:}

Andre Sominahouin, Roseric Azondekon, Sahabi Bio Bangana, Casimir Kpanou, Germain Gil Padonou, Razaki Ossè, Benoît Assogba, Fiacre Agossa, Filemon Tokponon, Martin Cossi Akogbeto. Natural Basis for the Proliferation of Malaria Vectors in Northern Benin (West Africa). European Journal of Biophysics. Vol. 9, No. 1, 2021, pp. 30-36. doi: 10.11648/j.ejb.20210901.15

Received: September 19, 2020; Accepted: September 29, 2020; Published: March 22, 2021

\begin{abstract}
Background: Malaria transmission is based on four essential elements: the vector, the parasite, humans and the environment. However, of the four elements, the environment is not sufficiently exploited. Methods: In the research presence carried out in 6 localities in North Benin, we used a microscopic vision of the health geographer, focusing on certain components of geography, entomology and meteorology to show what to show spatial disparities in malaria transmission using Arcgis 10.4, Global Mapper and SPSS 21.0 for regression and correlation analysis. Results: The results of our research show that the slopes are unstable. Also, the lower the altitude, the lower the water kinetics and consequently a lot of water stagnation favourable for the development of mosquito breeding sites. The explanatory power of the regression model means that $54.3 \%$ of the variation in positive mosquito breeding is explained by human population density. Conclusions: Benin must make significant progress in the elimination of malaria using a new effort to understand the ecology of vector mosquitoes based on spatial disparities in the fight against malaria.
\end{abstract}

Keywords: GIS, Climate, Anopheles gambiae (s.1.), Vector Control, Benin

\section{Introduction}

Malaria is caused by the Plasmodium parasite and transmitted by mosquito vectors of the Anopheles genus. The parasite and the vector that sustain malaria transmission require precise environmental conditions.

Malaria is limited to tropical regions, affecting more SubSaharan African countries where distribution of it transmission risk is unequal [1].

Therefore malaria result from the complexity of the relationships between parasits, hotes and environment.
[2] Various anthropogenic factors underline the spatial distribution of the risk of malaria transmission. It has previously been determined that agricultural and hydraulic developments, human mobility, forms of governance and urbanization may favor malaria transmission [3]. For example, infrastructure developments such as dam lakes, sanitation canals, and flooded rice paddies, increase the number of breeding sites of Anopheles mosquitoes.

The physical geography of northern Benin is a significant bedrock for the proliferation of malaria vectors in some areas: for example, rice farm areas and vegetable gardens, which were once not wet enough for permanent malaria 
transmission, are affected [4]. In northern Benin, malaria cases have increased in high-altitude areas, previously unaffected by the expansion of rice farming [5]. Moreover the presence of woodland and wooded savannas, hitherto too shady allows the development of the Anopheles larvae. These environment changes modify the spatial distribution of malaria vectors and extend the number of malaria transmission risk for months.

Anopheles mosquitoes were known to be associated to rural areas and hence, theoretically less common in urban areas [6]. In practice, the adaptation of certain species to urban areas and the practice of market gardening in or around the major agglomerations are at the origin of the persistence of anopheline populations in the city. The risk of malaria transmission is heterogeneous and varies over time. There is a great variation of risk within the same zone, even only a few kilometers away. The transmission varies over time according to the seasons but also according to the years depending on the level of climatic events. This study is initiated to investigate the physical basis of the distribution of malaria vectors in northern Benin in order to help the Ministry of Health to design better control strategies.

The slope is often qualified to participate in the description of natural sites such as mountains, hills, streams, canyons, banks, etc., either human constructions such as roads, railways, aqueducts, roofs, and pedestrian ways [7]. The slope of the ground is one of the essential parameters of the flow of the water in the rivers and more generally, the gravitational flow [8]. The slope can be a natural constraint for human settlement: it can be the scene of landslides, avalanches or landslides.

The purpose of these maps is either to prevent existing risks or to prevent the installation of new sources of danger [9].

\section{Materials and Methods}

\subsection{Study Area}

The study area covers the departments of Donga (Djougou, Ouake, Copargo health zone) and Alibori (Kandi, Gogounou, Segbana health zone). The municipalities of Djougou, Copargo and Ouaké are located between $9^{\circ} 18 ' 37$ "and $10^{\circ}$ 4'44" north latitude and between $1^{\circ} 19^{\prime} 27$ "and $2^{\circ} 13^{\prime} 55^{\prime \prime}$ east longitude. The municipalities of Gogounou, Kandi and Ségbana are located between $10^{\circ} 27^{\prime} 56$ "and $11^{\circ} 42^{\prime} 9^{\prime \prime} \mathrm{N}$ north latitude and between $2^{\circ} 8^{\prime} 39$ "and $3^{\circ} 54^{\prime} 20^{\prime \prime}$ longitude East.

\subsection{Mapping Method Used}

The following data was used:

1) The 19252, 19253, 19153, 19152, 19353, 19254 and 19254 Landsat OLI TIRS ortho-rectified satellite images respectively of July 2015 with a resolution of 30 $\mathrm{m}$.

2) The 2000 SRTM DEM satellite image, enhanced on June 26, 2009 with a resolution of $30 \mathrm{~m}$
3) The slope map is based on a digital terrain model with a resolution between 1 and 25 meters.

The GIS software, map processing and images used are respectively ArcGIS 10.3, Global Mapper v15. The laptop, scanner and digital camera facilitated the collection, archiving and processing of data. The topographic slope is the tangent of the slope between two points of a terrain, and therefore its angle to the horizontal [10].

We determined the density of the population by boroughs by dividing the number of inhabitants of the borough by its area expressed in square kilometers.

The demographic data and their area of the districts of the Alibori and Donga health zones came from the final results of the fourth General Population and Housing Census (GPHC4) of National Institute of Statistics and Economic Analysis (NISEA) and National Geographical Institute (NGI).

\subsection{Statistical Analyzes}

The global significance of the model and the regression coefficients are displayed according to the values of the two statistical tests: the statistical test $(\mathrm{F})$ and the student test $(\mathrm{t})$. The calculated values of these two statistical tests are given by SPSS 21 software. Five main variables are considered in this section. These are positive larval breedings, population density, topographic slope, elevation and temperature.

\subsection{Mapping of Land Use and Adult Mosquito Collections Methods}

Landsat image analysis consists of six steps: acquisition and pre-processing of data (choice of sites studied and preparation of data for the next steps), color composition, maximum likelihood classification, vectorization, validation, and analysis of results.

\section{Results}

\subsection{Influence of Altitudes in the Sanitary Zones}

Figure 1 is the altitude representation of the KGS and DCO sanitary zone. In Alibori department (Figure 1 a), the altitude varies from 185 to $408 \mathrm{~m}$ with a drop of $223 \mathrm{~m}$. The high altitude localities exist in all districts of the sanitary zone. In Angaradebou, district of Kandi the altitude gradient is oriented South-North. Areas of low altitude are located in the North and those of high altitudes in the South of the localities concerned. However, the higher the altitude values, the more the terrain slopes and more the kinetics of the water is high; there is therefore a strong runoff of water.

Similarly, the lower the altitude value the lower the kinetics of water. As a result, infiltration followed by water stagnation support the development of mosquito breeding sites.

The terrain is rugged with the predominance of a plateau which extends from Kandi to Gogounou. From an altitude of 200 to $300 \mathrm{~m}$, it is limited to the East by the valley of Sota and to the West by the valley of Alibori. The entire plateau slopes slightly towards the Niger valley. The morphology of 
the relief includes a series of cuesta with flat tops coated by ferruginous sandstone.

As for the DCO health zone, the altitude varies from 295 to $644 \mathrm{~m}$ with a drop of $349 \mathrm{~m}$ (Figure $1 \mathrm{~b}$ ). The high altitude zone forms a line crossing the localities of Copargo, Pabegou, Singré, Komdè, Tchalinga, Barei, Bariénou and Pélébina of the health zone. From theses localities, waters are drained towards their outlets which constitute the humid zones favorable to the proliferation of mosquitoes in the sanitary zone (Figure 1b). The kinetics of water in the district of Ouaké is strong, which means that runoff outweighs stagnation or infiltration. Consequently, the development of mosquito breeding sites is reduced in this district compared to other within the same department.

In total, it can therefore be deduced that the majority of the populations of localities of Donga and Alibori, notably those of Copargo, Bariénou, Komdè, Tchallinga, Sèmèrè II, Singré, Anadana, Djougou 1, Sonsoro, Sam, Ouèrè, Ségbana, Libantè, Liboussou and Kandi I are most exposed at risk of malaria transmission.

In the Donga, there is a watershed, the highest point of the relief that drains the waters to both sides. On the other hand, in the Alibori, several high points have been identified draining the mosquito larvae breeding grounds in several regions.

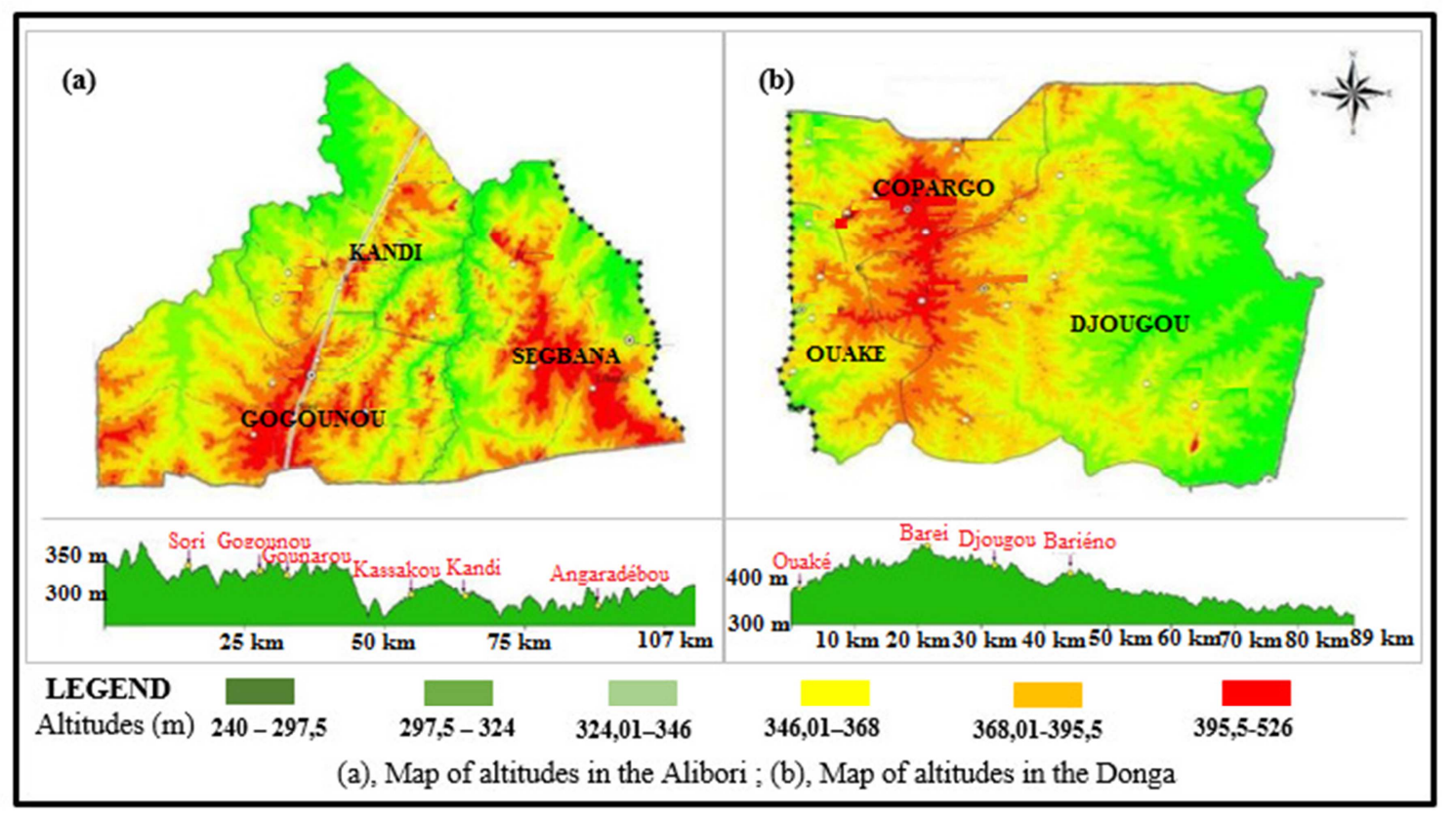

Figure 1. Map of altitudes in study zone.

\subsection{Comparative Study Between Positive Larval Breedings and the Physical Parameters of the Area}

From table 1, it appears that the average number of positive larval breeding per borough required is close to 844 . In these results, the standard deviation is 124.981. With normal data, most of the observations are based on nearly 7 standard deviations on each side of the average Anopheles mosquito breeding site. Similarly, the average density of its population is around $247.27 \mathrm{hts} / \mathrm{km} 2$, which produces the average standard deviation of 288.549. These normal data reveal that most of the observations are less than one standard deviation side of the average population density. In addition, with normal temperature data, most observations are divided into 5 standard deviations on each side of the mean temperature. The high standard deviation of positive larval breeding indicates that these variables are more widely dispersed than the density of the population.

From the analysis of the correlation matrix below, it is noted that there is a significant linear correlation (1\%) between the positive deposits of mosquitoes and the density of the human population. On the other hand, no correlation at $1 \%$ is significant between the positive deposits of mosquitoes and the other parameters (Table 2).

The equation of the multiple regression model is as follows: $\mathrm{Y}=\mathrm{a}+\mathrm{bx}+\mathrm{cy}+\mathrm{dz}+\mathrm{e} \beta$, so

PosLB $=1012.293+2.873$ DensPop -1.799 Alt +10.56 Slope - 12. 106 Temp. (Table 3).

This regression model shows the number of mosquito larva positive hosts equals 1012 by boroughs when the value of the other parameters is zero. In addition, Table 4 shows that the calculated Fisher statistic is 5.563. This statistic is read at the threshold of 0.002 or $0.2 \%$. This threshold is well below the critical threshold of $1 \%$. So the model is globally significant.

The explanatory power of the R-Square adjusted model $=$ 0.543 or $54.3 \%$. This means that $54.3 \%$ of the variations in positive mosquito breeding are explained by the density of the human population. The remaining $45.7 \%$ are explained by other variations that were not included in the model (Table 3). 
Table 1. Descriptive statistics of variables.

\begin{tabular}{lll}
\hline Variables & Average & Standard deviation \\
\hline Positive larval breeding & 844 & N \\
Population Density & 247.27 & 288.549 \\
Altitudes & 416.27 & 10.447 \\
Slopes & 22.5824 & 17.40925 \\
Temperature & 30.39 & 5.95 \\
\hline
\end{tabular}

Data source: Data of André Sominahouin

Table 2. Analysis of the bivariate correlation of the variables.

\begin{tabular}{|c|c|c|c|c|c|c|}
\hline & & PosLB & PopDens & Alt & Slopes & Temperature \\
\hline \multirow{3}{*}{ PosLB } & Correlation of Pearson & 1 & $0.652^{*}$ & 0.082 & 0.115 & 0.161 \\
\hline & Sig. (bilatérale) & & 0.000 & 0.649 & 0.525 & 0.372 \\
\hline & $\mathrm{N}$ & 33 & 33 & 33 & 33 & 33 \\
\hline \multirow{3}{*}{ PopDens } & Corrélation of Pearson & 0.652 & 1 & 0.045 & -0.115 & 0.029 \\
\hline & Sig. (bilatérale) & 0.000 & - & 0.802 & 0.524 & 0.871 \\
\hline & $\mathrm{N}$ & 33 & 33 & 33 & 33 & 33 \\
\hline \multirow{2}{*}{ Altitudes } & Corrélation of Pearson & 0.082 & 0.045 & 1 & -0.076 & -0.189 \\
\hline & $\mathrm{N}$ & 33 & 33 & 33 & 33 & 33 \\
\hline \multirow{3}{*}{ Slopes } & Corrélation of Pearson & 0.115 & -0.115 & -0.076 & 1 & -0.053 \\
\hline & Sig. (bilatérale) & 0.525 & 0.524 & 0.674 & - & 0.768 \\
\hline & $\mathrm{N}$ & 33 & 33 & 33 & 33 & 33 \\
\hline \multirow{3}{*}{ Temperature } & Corrélation of Pearson & 0.161 & 0.029 & -0.189 & -0.053 & 1 \\
\hline & Sig. (bilatérale) & 0.372 & 0.871 & 0.292 & 0.768 & - \\
\hline & $\mathrm{N}$ & 33 & 33 & 33 & 33 & 33 \\
\hline
\end{tabular}

Table 3. Coefficients of the regression correlation.

\begin{tabular}{llllll}
\hline \multirow{2}{*}{ Model } & & \multicolumn{2}{c}{ Unstandardized coefficients } & \multicolumn{2}{l}{ Standardized coefficients } \\
\cline { 3 - 5 } & & $\mathbf{A}$ & Std Error & Beta & \\
\hline \multirow{4}{*}{1} & (Constante) & 1012.293 & 2179 & - & 0.466 \\
& Population Density & 2.873 & 0.610 & 0.675 & 0.645 \\
& Altitudes & -1.799 & 2.862 & -0.091 & 0.000 \\
& Slopes & 10.560 & 16.663 & 0.091 & -629 \\
& Temperature & -12.106 & 49.020 & -036 & 0.634 \\
\hline
\end{tabular}

Table 4. Model Summary of the analyze de regression.

\begin{tabular}{llllll}
\hline Model & R & Ajusted R-square & Variation of F & df & \\
\hline 1 & $0.665^{\text {a }}$ & 0.543 & 5.563 & 4 & Sig. Variation de F \\
\hline
\end{tabular}

\section{Discussion}

The results presented in this study show that the topography of the KGS and DCO health zones have biophysical characteristics favorable to the development of mosquito vectors of malaria. The unevenly distributed vegetation is characterized by a strong presence of water and develops on a hierarchical spatial structure. This is indicated by the dominance of the open forest and the co-dominance of gallery forest, tree and shrub savannah and wooded savanna. This finding confirms Hoffman's (1985) report that species dominance is the key difference between disturbed and natural environments in the Sudan savannah zone [13]. Plant formations are fragmented at various levels not only by anthropogenic factors [14] but also by several natural (nonanthropogenic) factors. It can therefore be deduced that the biophysical base contributes greatly to the multiplication of vectors and that the vegetal formations of the classified savannas are wet and in the process of being grown with enough mosquitoes.

The weak rainfall patterns and annual rainfall in the KGS health zone confirm the influence of the Sahelian climate in the extreme north of Benin. This is related to the proximity of the Sahelian zone under constant continental flows of dry air from the Egyptian-Lybian anticyclone. These results are comparable to those of Houndénou and Hernandez [15], Houndénou [16], Vissin [17], and Totin et al [18]. The number of tasks is relatively high for all plant formations except for the clear forest in the classified forests of Kétou, Ouémé-Boukou and the open forest and grassy savannah in the classified forest of Dogo [19].

According to Saunders et al., [20], forests will be more vulnerable to human activities when the number of tasks is high.

Through June 2014, there were 17 published studies that have used geospatial technologies (GIS, GPS and/or RS) to understand and predict malaria risks [21-32], develop malaria risk maps, [32, 33] and provide findings for targeted interventions strategies in Bangladesh. To supply feedback to 
the National Malaria Control Program (NMCP), national malaria risk maps were produced [13, 34]. Long-term average monthly rainfalls and minimum/maximum temperatures ranges were interpolated, and elevation and vegetation coverage data were obtained using satellite imagery. GIS was also employed to develop maps of posterior distributions of predicted prevalence [30].

Our work is consistent with that of Jaissa Man realizes in 2017 which showed that mosquitoes are one of the most prevalent and troublesome menaces that come with rains in India. This is a particularly rampant problem in places like Bengal, Karnataka, Maharashtra, Tamil Nadu, and areas towards the North East as these environments are favourable for mosquito breeding. Yet, other areas too, witness issues like stagnant water and poor drainage, which also cause mosquitoes to multiply.

In addition, the study area of Alibori is essentially based on its specialization in cotton cultivation (Northern Benin Cotton Zone). This area is watered by several tributaries of the Niger River and is influenced by the continental trade wind as early as November. This favors the prevalence of $A n$. gambiae s.l main vector of malaria in the department.

With the abundance of malaria vector breeding sites in the districts where the Benin NMCP extended IRS, Geographic Information System and Remote Sensing can be used to monitor vector's oviposition site/breeding ground and thereby predict their abundance. There has been a proliferation of some vector species in those districts with extended IRS with an increase in stagnant water, particularly during the rainy seasons, from deforestation for agricultural purposes, providing more breeding sites for the mosquitoes [35]. It has been noted that during the dry and malaria offseasons, cases were found clustered around natural streams and canals in the Chittagong Hill Tracts region [34]. Locating land use patterns across the vector breeding sites and using remotely sensed climatic environmental data, particularly temperature, humidity, and rainfall as they correlate to malaria outbreaks, could provide useful information on the planning of vector control in this region. This same approach was applied in Indonesia and revealed malaria vector abundance in certain areas where malaria control programs were then implemented with significant success [36]. The topographic variable can also be remotely-sensed to predict malaria vector's breeding site in malaria endemic areas [37].

Our results are consistent with those of Tadesse et al in 2011 showing the influence of the physical characteristics of the larval habitat. In fact, the results of the multiple regression analysis showed that vegetation, water transparency, precipitation, and fauna were more important in explaining Anopheles' larval abundance than other variables. On the other hand, the nature of the bottom surface and the microhabitat were more important in determining the Culex larval density than the transparency of the water.

\section{Conclusion}

The fight against malaria vectors must no longer ignore cartography, a real information and decision-making tool for predicting malaria risks. GIS techniques and other additional interventions are then capable of reducing residual malaria transmission in order to target vectors that escape the main control tools.

In order to eradicate malaria in these high-risk areas, it is recommended to make sufficient use of environmental aspects, to asphalt these areas in order to clean up and improve the living environment of the populations.

\section{Ethics Approval and Consent to Participate}

The protocol of this study was evaluated and approved by the Institutional Ethical Committee of CREC (IECC) (Grant No IORG005698). Prior to their involvement in this study, voluntary mosquito collectors have been trained and gave their consent. They were checked up, taken care in case of confirmed malaria case and, vaccinated against yellow fever.

\section{Consent for Publication}

Not applicable.

\section{Availability of Data and Materials}

The data used and/or analysed in this study are available from the corresponding author on reasonable request.

\section{Competing Interests}

The authors declare that they have no competing interests.

\section{Funding}

This study was financially supported by the US President's Malaria Initiative (PMI) through the United States Agency for International Development (USAID) Africa Indoor Residual Spraying Project (AIRS).

\section{Authors' Contributions}

AS, MCA, RA, SL, RO, GGP conceived the study. AS, MCA, BA, FT, ASS have participated in the design of the study. Entomologic data was collected by AS, RL, ASS, FT, $\mathrm{CH}$ and laboratory analysis was carried out by AS, BA, FA. AS drafted the manuscript.

Statistical data analysis by BA. FD, FT, RO, and ASS critically revised the manuscript for intellectual content. All authors read and approved the final manuscript.

\section{Acknowledgements}

We are grateful to the President's Malaria Initiative which supported financially this study. We would also like to acknowledge Martin Akogbéto who provided technical 
support to the study and critically revised the manuscript.

\section{References}

[1] WHO (2017). Malaria elimination: report from the inaugural global forum of countries with potential to eliminate malaria by 2020. Wkly Epidemiol Rec.; 92 (39): 578-586.

[2] Daniel, M. P., Verena I. C., Sasithon P., Rose M. G., \& François H. N. (2015); Malaria ecology along the ThailandMyanmar border. Malaria journal. 14 (388).

[3] Mark, L. W., Donald, J. K., Emmanuel A., Myriam A., Laura C., Marcelo U. F., Daouda N., Don P. M., \& Alex E. (2015). Urban Malaria: Understanding its Epidemiology, Ecology, and Transmission across Seven Diverse ICEMR Network Sites. Am J Trop Med Hyg. 93 (3 Suppl): 110-123.

[4] Humphrey D. Mazigo, Susan F. Rumisha, Mercy G. Chiduo, Veneranda M. Bwana, \& Leonard E. G. (2017). Mboera. Malaria among rice farming communities in Kilangali village, Kilosa district, Central Tanzania: prevalence, intensity and associated factors. Infect Disease Poverty, 6: 101.

[5] Humphrey D. M., Isolide S. M., Susan F. R., Eliningaya J. K.., \& Leonard E. G. M. (2019). Rice farmers' perceptions and acceptability in the use of a combination of biolarvicide (Bacillus thuringiensis var. israeliensis) and fertilizers application for malaria control and increase rice productivity in a rural district of central Tanzania. Malaria Journal. volume 18, Article number: 71.

[6] Pages et al., (2007) Themba Mzilahowa, Madalitso LukaBanda, Veronica Uzalili, Don P Mathanga, Carl H Campbell, Jr., Mavuto Mukaka, \& John E Gimnig. Risk factors for Anopheles mosquitoes in rural and urban areas of Blantyre District, southern Malawi. Malawi Med J. 2016 Dec; 28 (4): 154-158.

[7] Santa C., Valley Water District (SCVWD).(2017). West valley page of the Santa Clara Valley Water District web site. http://www.valleywater.org/services/WestValley.aspx

[8] Drobot, R.., and Serban P. (1999). Aplicatii de hidrologie si gospodarirea apelor (Application of Hydrology and Water Resources Management). Ed. HGA, Bucuresti, Romania.

[9] Le Baux, V. R. (1990). “ Les risques majeurs de S. D. A. U. R. F': Maitrise de l'urbanisation autour des sites industriels à haut risque, Guide édité par le Secrétaire d'Etat auprès du Premier Ministre chargé de l'Environnement, Délégation aux Risques Majeurs au ministère de l'environnement. Paris, 164.

[10] Chapter 3 - elements of topography http://www.fao.org/docrep/r4082e/r4082e04.htm\#TopOfPagef

[11] Geier, M., \& Boeckh J. A. (1999). new Y-tube olfactometer for mosquitoes to measure the attractiveness of host odours. Entomol Exp Appl.; 92: 9-19. doi: 10.1046/j.15707458.1999.00519.x. [CrossRef]

[12] Yaw A. A., Andrew K. G., and Guiyun Y. 2012. The Ecology of Anopheles Mosquitoes under Climate Change: Case Studies from the Effects of Environmental Changes in East Africa Highlands. HSS public-access, Author manuscript, 1249: 204-210.

[13] Sinsin, B., \& Kampmann. D., (eds) Cotonou \& Frankfurt. (2010). Atlas de la Biodiversité de l'Afrique de l'Ouest
Biodiversity Atlas of West Africa, Tome | Volume I: Benin /Main ISBN 978-3-9813933-0-9, hardcover ISBN 978-39813933-3-0, paperback.

[14] Sare B. A, Totin V. S. H, Houssou C. S, Sinsin B. (2015). Variation du régime pluviométrique de la périphérie de la réserve de biosphère transfrontalière $\mathrm{du} \mathrm{w}$ au Bénin. XXVIIIe Colloque de l'Association Internationale de Climatologie, Liège. 603.

[15] Houndénou, C. (1999). Variabilité climatique et maïsiculture en milieu tropical humide. L'exemple du Bénin, diagnostic et modélisation. Thèse de Doctorat de l'Université de Bourgogne Dijon, France, 390 p.

[16] Vissin, E. W. (2007). Impact de la variabilité climatique et de la dynamique des états de surface sur les écoulements du bassin béninois du fleuve Niger. Thèse de Doctorat de l'Université de Bourgogne Dijon, France, 280 p.

[17] Vodounon T. S. H., Totin V, Djohy L. G., Amoussou E., Boko M. (2016). Instabilité du régime climatique et dynamique des systèmes pastoraux dans la commune de sinende au Nord-Benin. Revue des Sciences de l'Environnement, Laboratoire de Recherches Biogéographiques et d'Etudes Environnementales (Université de Lomé), 2016, pp. 157-178. ffhal-01552159f.

[18] Harbach R. (1994). Review of the internal classification of the genus Anopheles (Diptera: Culicidae): the foundation for comparative sytematics and phylogenetic research. Bull Entomol Res,; 84: 331-42.

[19] UEMOA, les grandes orientations de la politique commune d'amelioration de de l'environnement (PCAE), annexe 2.

[20] a, b et c Annales des mines: Recueil de mémoires sur l'exploitation des mines, Paris, Treuttel et Wurtz, 1817, 536 p., p. 270.

[21] a et b Charles, B., V., \& Charles V. (1869). Éléments de géométrie descriptive, Paris, Hachette,, 140 p., p. 122.

[22] Haque, U., Magalhaes, R. J. S., Reid, H. L., Clements, A. C. A.; Ahmed, S. M.; Islam, A.; Yamamoto, T.; Haque, R.; \& Glass, G. E. (2010). Spatial prediction of malaria prevalence in an endemic area of Bangladesh. Malar. J. 9120.

[23] Haque, U.; Huda, M.; Hossain, A.; Ahmed, S. M.; Moniruzzaman, M.; \& Haque, R. (2009). Spatial malaria epidemiology in Bangladeshi highlands. Malar. J. 8-185.

[24] Haque, U., Sunahara, T., Hashizume, M.; Shields, T.; Yamamoto, T.; Haque, R.; \& Glass, G. E. (2011). Malaria prevalence, risk factors and spatial distribution in a hilly forest area of Bangladesh. PLoS One., 6, doi: 10.1371/journal.pone.0018908.

[25] Haque, U.; Glass, G. E.; Bomblies, A.; Hashizume, M.; Mitra, D.; Noman, N.; Haque, W.; Kabir, M. M.; Yamamoto, T.; \& Overgaard, H. J. (2013). Risk factors associated with clinical malaria episodes in Bangladesh: A longitudinal study. Am. $J$. Trop. Med. Hyg., 88, 727-732.

[26] Haque, U.; Scott, L. M.; Hashizume, M.; Fisher, E.; Haque, R.; Yamamoto, \& T.; Glass, G. E. (2012). Modelling malaria treatment practices in Bangladesh using spatial statistics. Malar. J., 11, doi: 10.1186/1475-2875-11-63. 
[27] Galagan, S. R.; Prue, C. S.; Khyang, J.; Khan, W. A.; Ahmed, S.; Ram, M.; Alam, M. S.; Haq, M. Z.; Akter, J.; \& Streatfield, P. K. (2014). The practice of jhum cultivation and its relationship to plasmodium falciparum infection in the Chittagong hill districts of Bangladesh. Am. J. Trop. Med. Hyg., 91, 374-383.

[28] Rahman, A.; Kogan, F.; Roytman, L. (2006). Short report: Analysis of malaria cases in Bangladesh with remote sensing data. Am. J. Trop. Med. Hyg., 74, 17-19.

[29] Rahman, A.; Krakauer, N.; Roytman, L.; Goldberg, M.; \& Kogan, F. (2010). Application of advanced very high resolution radiometer (AVHRR)-based vegetation health indices for estimation of malaria cases. Am. J. Trop. Med. Hyg., 82, 1004-1009.

[30] Khan, W. A.; Sack, D. A.; Ahmed, S.; Prue, C. S.; Alam, M. S.; Haque, R.; Khyang, J.; Ram, M.; Akter, J.; \& Nyunt, M. M. (2011). Mapping hypoendemic, seasonal malaria in rural Bandarban, Bangladesh: A prospective surveillance. Malar. J., 10, doi: 10.1186/1475-2875-10-124.

[31] Haque, U.; Magalhaes, R. J. S.; Reid, H. L.; Clements, A. C. A.; Ahmed, S. M.; Islam, A.; Yamamoto, T.; Haque, R.; \& Glass, G. E. (2010). Spatial prediction of malaria prevalence in an endemic area of Bangladesh. Malar. J., 9, doi: $10.1186 / 1475-2875-9-120$.

[32] Haque, U.; Ahmed, S. M.; Hossain, S.; Huda, M.; Hossain, A.; Alam, M. S.; Mondal, D.; Khan, W. A.; Khalequzzaman, M.;
\& Haque, R. (2009). Malaria prevalence in endemic districts of Bangladesh. PLoS One, 4, e6737.

[33] Glass, G.; Alam, M. S.; Khan, W. A.; Sack, D. A.; \& Sullivan, D. J. (2011). Spatial clustering of malaria cases during lowtransmission season in Kuhalong, Bangladesh. In Proceedings of the 13th Ascon Conference, Dhaka, Bangladesh.

[34] Alam, M. S.; Chakma, S.; Al-Amin, H. M.; Elahi, R.; Mohon, A. N.; Khan, W. A.; Haque, R.; Glass, G. E.; Sack, D. A.; \& Sullivan, D. J. (2012). Role of artificial containers as breeding sites for anopheline mosquitoes in Malaria hypo endemic areas of rural Bandarban, Bangladesh: Evidence form a baseline survey. In Proceedings of the Astmh Conference, Atlanta, GA, USA.

[35] Stoops, C. A.; Gionar, Y. R.; Shinta; Sismadi, P.; Rachmat, A.; Elyazar, I. F.; \& Sukowati, S. (2008). Remotely-sensed land use patterns and the presence of anopheles larvae (diptera: Culicidae) in Sukabumi, West Java, Indonesia. J. Vector. Ecol., $33,30-39$.

[36] Nmor, J. C.; Sunahara, T.; Goto, K.; Futami, K.; Sonye, G.; Akweywa, P.; Dida, G.; Minakawa, N. (2013). Topographic models for predicting malaria vector breeding habitats: Potential tools for vector control managers. Parasit. Vector, 6, doi: 10.1186/1756-3305-6-14.

[37] Tadesse, D., Mekonnen, Y., \& Tsehaye, A. (2011). Characterization of Mosquito Breeding Sites in and in the Vicinity of Tigray Microdam. Ethiop J Health Sci. Mar; 21 (1): 57-66. 